\title{
Genomic Integrity Is Favourably Affected by High-Intensity Interval Training in an Animal Model of Early-Stage Chronic Kidney Disease
}

\author{
Patrick S. Tucker ${ }^{1,2} \mathbb{B}$, Aaron T. Scanlan ${ }^{1,2}$, Rebecca K. Vella ${ }^{3}$ and Vincent J. Dalbo ${ }^{1,2^{*}}$
}

\begin{abstract}
Background: Chronic kidney disease (CKD) is an irreversible disease that diminishes length and quality of life. Emerging evidence suggests CKD progression and genomic integrity are inversely and causally related. To reduce health complications related to CKD progression, chronic aerobic exercise is often recommended. To date, appraisals of differing modes of exercise, along with postulations regarding the mechanisms responsible for observed effects, are lacking.

In order to examine the ability of aerobic exercise to encourage improvements in genomic integrity, we evaluated the effects of 8 weeks of high-intensity interval training $\left(H I I T ; 85 \% \mathrm{VO}_{2 \text { max }}\right.$ ), low intensity training (LIT; 45-50 \% VO $\mathrm{V}_{2 \max }$ ), and sedentary behaviour (SED), in an animal model of early-stage CKD.
\end{abstract}

Methods: To assess genomic integrity, we examined kidney-specific messenger RNA (mRNA) expression of genes related to genomic repair and stability: Fan1, Mre11a, and telomere length as measured by T/S ratio.

Results: Following HIIT, mRNA expression of Fan1 was significantly up-regulated, compared to SED $(p=0.026)$ and T/S ratio was significantly increased, compared to SED $(p<0.001)$ and LIT $(p=0.002)$.

Conclusions: Our results suggest that HIIT is superior to SED and LIT as HIIT beneficially influenced the expression of genes related to genomic integrity.

\section{Key Points}

1. CKD progression and genomic integrity are inversely and causally related.

2. To reduce complications related to CKD progression, chronic aerobic exercise is often recommended. Recently, clinicians and researchers have suggested that high-intensity interval training may be more beneficial, relative to low intensity training.

\footnotetext{
* Correspondence: v.dalbo@cqu.edu.au

${ }^{1}$ Clinical Biochemistry Laboratory, School of Medical and Applied Sciences, Central Queensland University, Bruce Highway, Building 81, Room 1.11, Rockhampton 4702, Queensland, Australia

${ }^{2}$ Human Exercise and Training Laboratory, Central Queensland University,

Bruce Highway, Building 81, Rockhampton 4702, Australia

Full list of author information is available at the end of the article
}

3. Following high-intensity interval training, mRNA expression of Fan1 was significantly up-regulated, relative to sedentary behaviour $(p=0.026)$ and $\mathrm{T} / \mathrm{S}$ ratio was significantly increased, relative to sedentary behaviour $(p<0.001)$ and low intensity training $(p=0.002)$.

4. Our results suggest that high-intensity interval training is superior to sedentary behaviour and low-intensity training; high-intensity interval training beneficially influenced the expression of genes related to the preservation of genomic integrity.

\section{Background}

Chronic kidney disease (CKD) is an irreversible disease, characterised by a progressive decline in kidney function. Patients with end-stage renal disease (stage 5 CKD) are required to undergo renal replacement therapy (RRT), a term referring to life-long dialysis or kidney transplant. 
RRT represents a substantial financial burden on the Australian healthcare system, with yearly per-patient expenditure averaging nearly $\$ 55,000$ (AUD) in 2012 [1].

While increases to RRT-related expenditure are troubling, the physiological consequences of CKD are most worrisome. The risks of comorbidity and mortality increase exponentially as renal function declines, resulting in a life expectancy that is decreased to such an extent that many CKD patients do not survive long enough to require RRT $[2,3]$.

The primary mechanisms responsible for the progression of CKD are revealed in the interactions between free radicals and reactive oxygen species (ROS), renal DNA, and inflammation mediators. For example, renal ROS, such as hydroxyl radicals, harmfully interact with nuclear and mitochondrial DNA bases [4-6]. This ROS-mediated damage to renal DNA may result in (a) inter-strand DNA, intra-strand DNA, and protein-DNA crosslinking that blocks DNA replication, leading to cell death [5-7] or (b) DNA strand breakage which results in cell death, if unrepaired, or genomic deletions and mutations, if repaired incorrectly [5-7]. ROS-mediated damage also activates the inflammatory response, in an effort to repair cellular and molecular injuries, which may encourage downstream DNA damage via the release of superoxide that is born of phagocytic activity [7-9]. Given the cyclical nature of this process, it becomes apparent that reducing and repairing DNA damage in the kidney is essential in terms of slowing CKD progression (Fig. 1).

Fortunately, mechanisms exist to repair damaged DNA. The Fanconi Anaemia (FA) pathway is a repair pathway devoted to repairing DNA inter-strand crosslinks (ICL) [10]. A crucial component of the FA pathway, FAassociated nuclease 1 (FAN1), a protein encoded by a gene of the same name (Fan1), makes nucleolytic incisions around the ICL $[11,12]$, thereby allowing additional molecules to complete repairs to damaged DNA. Evidence suggests depletion or mutation of FAN1 protein increases ICL [13], apoptosis [14], and kidney damage [14]. Unfortunately, ICL are not the only manifestation of DNA damage; DNA double-strand breaks are another form of damage that may result in genomic corruption.

Meiotic recombination 11 homolog A (MRE11A) is a nuclear protein involved in the repair of DNA double-strand breaks [15]. Encoded by the gene Mre11a, this protein is the core of the Mre11-Rad50-Nbs1 (MRN) complex,

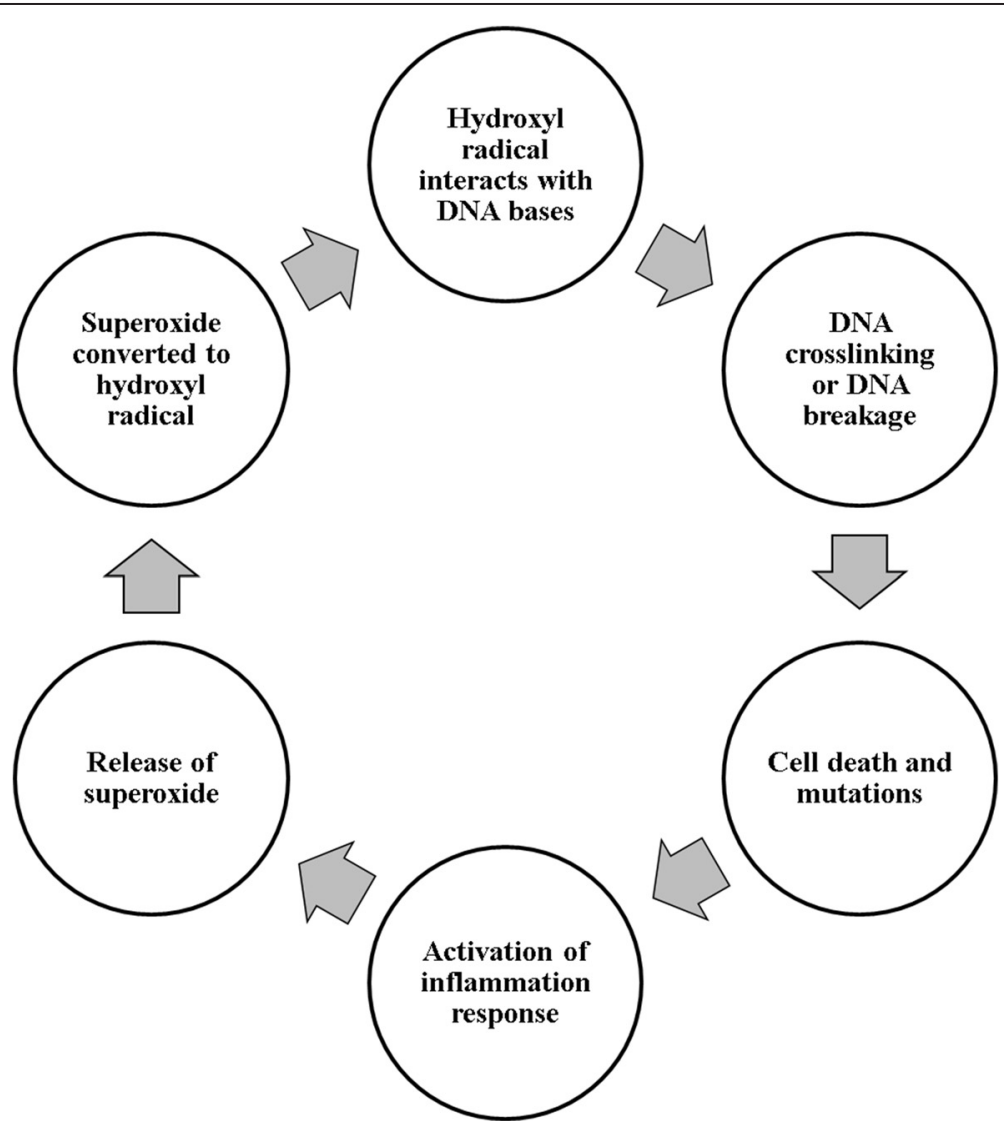

Fig. 1 The primary mechanisms responsible for the progression of CKD: interactions between free radicals and reactive oxygen species, renal DNA, and inflammation mediators 
providing the nuclease activity that is required for nonhomologous joining of DNA ends [15]. Evidence suggests the MRN complex is activated by hypertonic, hyperosmotic salt in renal tissue [16], and cisplatin-induced nephrotoxicity [17], allowing for the repair of double-strand breaks in renal tissue that would otherwise suffer DNA damage.

Mre11a gene expression also plays a role in telomere preservation, via $\mathrm{MRN}$-mediated ataxia-telangiectasia mutated kinase signalling in response to telomere shortening or telomere damage $[18,19]$. The rate at which telomeres become depleted is not constant, allowing telomere length to serve as a predictor of life expectancy [20] and mortality [21]. Evidence suggests that patients with CKD have shorter telomeres and accelerated telomere shortening, relative to healthy counterparts [22, 23].

Despite their influence on molecular perturbations associated with CKD progression, few studies have examined the messenger RNA (mRNA) expression of Fan1, Mre11a, and telomere length in the context of CKD $[14,17,22]$. Furthermore, data describing potential modulators of mRNA expression of Fan1, Mre11a, and telomere length, in the context of CKD progression, are unavailable. Chronic aerobic exercise training has emerged as a promising therapy in terms of reducing CKD-related damage and slowing CKD progression [24-27]. Recently, clinicians and researchers have suggested that high-intensity interval training (HIIT) (generally, $\left.\approx 85 \% \mathrm{VO}_{2 \max }\right)$ may elicit greater benefits, relative to traditional light intensity training (generally, $\approx 50 \% \mathrm{VO}_{2 \max }$ ) [27-29]. However, the underlying mechanisms that allow for this have yet to be fully described. The purpose of the present study was to determine the effect of chronic HIIT (four times per week for 8 weeks) on the kidney-specific mRNA expression of molecules associated with genomic integrity (Fan1, Mre11a, and telomere length as measured by $\mathrm{T} / \mathrm{S}$ ratio) in an animal model of early-stage CKD. It was hypothesised that HIIT would exert a more beneficial effect on Fan1, Mre11a, and T/S ratio, relative to sedentary behaviour (SED) and low intensity training (LIT).

\section{Note}

In the discussion of this manuscript, data pertaining to genomic integrity are considered alongside previously reported data pertaining to CKD-related clinical markers (plasma albumin and kidney weight-body weight ratios) [30] and renal-specific mRNA expression of antioxidant enzyme genes (superoxide dismutase and catalase) [31] in the same animals.

\section{Methods}

\section{Animals and General Overview}

Male spontaneously hypertensive rats (SHR) $(n=39)$ (Animal Resource Centre, Canning Vale, WA, Australia) were housed in a temperature-controlled room $\left(22-25^{\circ} \mathrm{C}\right)$ with a dark-light cycle of $12: 12 \mathrm{~h}$ and provided ad libitum access to standard laboratory chow and water. At the time of arrival, rats were 4-5 weeks old. Following a 2-week habituation period, allowing for acclimatisation to their new environment, all rats underwent a unilateral nephrectomy (6-7 weeks old). Following surgery, rats were allowed to recover for 2 weeks prior to the initiation of an 8-week exercise intervention. Blood pressures, body weights, and body lengths were recorded at pre-surgery, baseline (preexercise), 4 weeks (mid-intervention), and 8 weeks (postintervention). Following the 8-week intervention, rats were euthanised $24 \mathrm{~h}$ following their last bout of exercise and tissues were collected for subsequent analysis. All research procedures were granted prior approval by an institutional Animal Ethics Committee (Animal Ethics Committee of Central Queensland University, project A13/11-305). This study was supported using internal funds awarded as part of Research Higher Degree study at Central Queensland University.

\section{Anesthetisation and Euthanasia Procedures}

Prior to nephrectomy, rats were anesthetised with tiletamine/zolazepam (Zoletil) $(25 \mathrm{mg} / \mathrm{kg})$ and xylazine $(10 \mathrm{mg} /$ $\mathrm{kg})$. For pain relief, meloxicam $(2 \mathrm{mg} / \mathrm{kg})$ was injected once daily for 2 days following nephrectomy. Prior to blood pressure readings, rats were anesthetised with tiletamine/zolazepam $(25 \mathrm{mg} / \mathrm{kg})$. Saline was injected subcutaneously following each anesthetisation to help avoid dehydration. Prior to being euthanised, rats were given a pentobarbitone sodium (Lethabarb) injection $(1.5 \mathrm{mg} / \mathrm{kg})$.

\section{Exercise Protocol}

Rats were randomly assigned to one of three treatment groups: sedentary (SED, $n=12$ ), low-intensity training (LIT, $n=13$ ), and high-intensity interval exercise (HIIT, $n=14$ ). The number of animals assigned to each group was dependant on the form and intensity of exercise, as the possibility existed that aerobic exercise may have proven too strenuous, resulting in the need to withdraw an animal from the experiment. However, there were no adverse events in any group, suggesting that aerobic exercise was well-tolerated in this disease model.

At 8-9 weeks of age, rats in the LIT and HIIT groups began treadmill running for 8 weeks. An identical 5-min warm-up $(15 \mathrm{~m} / \mathrm{min})$ was performed by both training groups before each exercise session. Rats in the LIT group exercised at a treadmill speed of $15 \mathrm{~m} / \mathrm{min}$ with an incline of $1^{\circ}\left(45-50 \% \mathrm{VO}_{2 \max }\right)$ [32], up to $33 \mathrm{~min}$ per day, 4 days per week, for 8 weeks. Rats in the HIIT group exercised at a treadmill speed of up to $50 \mathrm{~m} / \mathrm{min}$ with an incline of up to $10^{\circ}\left(\approx 85 \% \mathrm{VO}_{2 \max }\right)$ [32], $30 \mathrm{~min}$ per day (2-min stationary period followed by 1-min sprint $\times 10$ repetitions), 4 days per week, for 8 weeks. To permit adequate adaptation to treadmill running, thereby 
allowing each exercise session to be completed in its entirety, exercise training was progressive. By the beginning of the fourth week of training, all rats were performing exercise sessions at maximum intensity/duration-the exercise effort remained constant for the remaining 5 weeks of training. In an effort to standardise variables related to exercise training, while simultaneously allowing for the comparison of different intensities, exercise sessions for LIT and HIIT groups were matched based on distance travelled per session. That is, despite the difference in exercise intensity between groups, LIT and HIIT rats travelled the same distance $( \pm 1 \mathrm{~m})$ during each exercise session, with distances progressing in unison from $\approx 200 \mathrm{~m}$ per session in week 1 to $\approx 500 \mathrm{~m}$ per session in week 8 (Table 1 -republished with permission [27]).

\section{Tissue Homogenisation and mRNA Isolation}

Tissue used for analyses were chosen based on tissuespecific transcriptomic work performed in SHR [33]. In this study, renal tissue consisted specifically of renal cortex as mRNA is differentially expressed dependant on the type of renal tissue [34]. Approximately $100 \mathrm{mg}$ $( \pm 10 \mathrm{mg}$ ) of tissue from the renal cortex was homogenised in $1 \mathrm{ml}$ of TRI-reagent, using the TRI-reagent method (Sigma Aldrich, St. Louis, MO, USA). Samples were then centrifuged at $12,000 \times g$ for $10 \mathrm{~min}$ at $4{ }^{\circ} \mathrm{C}$. The resulting supernatant was transferred to a new microtube and incubated for $5 \mathrm{~min}$, at room temperature, to allow for disassociation of the nucleoprotein complex. Following incubation, $0.2 \mathrm{ml}$ of chloroform was added before this solution was mixed and then incubated for $3 \mathrm{~min}$. Samples were then centrifuged at $12,000 \times g$ for $15 \mathrm{~min}$ at $4{ }^{\circ} \mathrm{C}$. The resulting supernatant was transferred to a new microtube. Following this separation, $500 \mu \mathrm{l}$ of 2-propanol was added to each microtube. Microtubes were incubated at room temperature for $10 \mathrm{~min}$ and then centrifuged at $12,000 \times \mathrm{g}$ for $10 \mathrm{~min}$ at $4{ }^{\circ} \mathrm{C}$. The resulting supernatant was removed, leaving behind an mRNA pellet. The mRNA pellet was exposed to two ethanol washes ( $1 \mathrm{ml}, 75 \%)$. Following each wash, microtubes were vortexed and centrifuged at $7500 \times g$ for $5 \mathrm{~min}$ at $4{ }^{\circ} \mathrm{C}$. The mRNA pellets were then allowed to air dry under a fume hood before being dissolved in $30 \mu \mathrm{l}$ of RNase-free water. A 260/280 ratio was calculated to assess mRNA purity, with all ratios falling within commonly accepted parameters. The diluted mRNA samples were stored at $-80^{\circ} \mathrm{C}$ until later analyses.

\section{Total mRNA Determination and Reverse Transcription}

Total mRNA concentrations from each sample were determined using a spectrophotometer (NanoDrop 2000c, Thermo Scientific, Wilmington, DE, USA). Next, mRNA concentrations were adjusted to $400 \mathrm{ng} / \mu \mathrm{l}$ by diluting the crude total mRNA extracts with RNase-free water. The standardised solutions of total cellular mRNA were reverse transcribed to synthesise complimentary DNA (cDNA) using a high-capacity cDNA reverse transcription kit (Applied Biosystems, Foster City, CA, USA). Briefly, $\times 2$ RT master mix was prepared per kit instructions. Next, $10 \mu \mathrm{l}$ of RT mix was added (and mixed via pipette trituration) to $10 \mu \mathrm{l}$ of the standardised mRNA solution. These samples were placed on a thermal cycler (T100 Thermal Cycler, Bio-Rad, Gladesville, NSW,

Table 1 Detailed description of 8-week exercise protocol. Reproduced from Tucker et al. [27] with permission

\begin{tabular}{|c|c|c|c|c|c|c|c|c|c|c|}
\hline Group & Variable & Measure & Wk1 & Wk2 & Wk3 & Wk4 & Wk5 & Wk6 & Wk7 & Wk8 \\
\hline SED & NA & NA & NA & NA & NA & NA & NA & NA & NA & NA \\
\hline \multirow{7}{*}{$\begin{array}{l}\mathrm{LIT} \\
45-50 \% \mathrm{VO}_{2 \max }\end{array}$} & Max. speed & Meters/min & 15 & 15 & 15 & 15 & 15 & 15 & 15 & 15 \\
\hline & Incline & Degrees & 1 & 1 & 1 & 1 & 1 & 1 & 1 & 1 \\
\hline & Duration & Minutes & 13.3 & 20 & 26.6 & 33.3 & 33.3 & 33.3 & 33.3 & 33.3 \\
\hline & Intensity & \multicolumn{9}{|c|}{ Constant treadmill speed and constant treadmill incline } \\
\hline & Frequency & Bouts/week & 4 & 4 & 4 & 4 & 4 & 4 & 4 & 4 \\
\hline & Distance per bout & Meters & 199.5 & 300 & 399 & 499.5 & 499.5 & 499.5 & 499.5 & 499.5 \\
\hline & Distance per week & Meters & 798 & 1200 & 1596 & 1998 & 1998 & 1998 & 1998 & 1998 \\
\hline \multirow{7}{*}{$\begin{array}{l}\text { HIIT } \\
\approx 85 \% \mathrm{VO}_{2 \max }\end{array}$} & Max. speed & Meters/min & 20 & 30 & 40 & 50 & 50 & 50 & 50 & 50 \\
\hline & Incline & Degrees & 5 & 10 & 10 & 10 & 10 & 10 & 10 & 10 \\
\hline & Duration & minutes & 30 & 30 & 30 & 30 & 30 & 30 & 30 & 30 \\
\hline & Intensity & \multicolumn{9}{|c|}{ 2-min stationary period followed by 1 -min sprint period $\times 10$ reps } \\
\hline & Frequency & Bouts/week & 4 & 4 & 4 & 4 & 4 & 4 & 4 & 4 \\
\hline & Distance per bout & Meters & 200 & 300 & 400 & 500 & 500 & 500 & 500 & 500 \\
\hline & Distance per week & Meters & 800 & 1200 & 1600 & 2000 & 2000 & 2000 & 2000 & 2000 \\
\hline
\end{tabular}


Australia) set to run at $25{ }^{\circ} \mathrm{C}$ for $10 \mathrm{~min}, 37{ }^{\circ} \mathrm{C}$ for $120 \mathrm{~min}$, and $85{ }^{\circ} \mathrm{C}$ for $5 \mathrm{~min}$. Following reverse transcription, the resulting cDNA template concentrations were diluted to $5 \mathrm{ng} / \mu \mathrm{l}$ by adding RNase-free water. The standardised cDNA solutions were frozen at $-80{ }^{\circ} \mathrm{C}$ until quantitative reverse transcription polymerase chain reaction (qRT-PCR) was performed.

\section{Quantitative Reverse Transcription Polymerase Chain Reaction Analysis}

Forward and reverse oligonucleotide primer pairs were developed using National Centre for Biotechnology Information's (NCBI, Bethesda, MD, USA) Primer Designer Tool before being commercially synthesised (GeneWorks, Hindmarsh, SA, Australia) (Table 2). Gapdh was used as an internal reference gene for detecting relative change in the quantity of target mRNA due to its consideration as a constitutively expressed housekeeping gene following exercise training [35]. Following the examination of primer efficiencies, qRT-PCR reactions were mixed. Reactions contained the following mixture: $2.5 \mu \mathrm{l}$ of prepared cDNA template, $5 \mu \mathrm{l}$ of SYBR Select Master Mix (Life Technologies, Mulgrave, Victoria, Australia), $0.5 \mu \mathrm{l}$ of sense and anti-sense primers, and $1.5-\mu \mathrm{l}$ RNasefree water. Following the mixture of each reaction, qRTPCR was performed with a thermal cycler (Rotor-Gene Q, Qiagen, Venlo, Netherlands). The amplification sequence involved an initial 10 -min cycle at $95{ }^{\circ} \mathrm{C}$, followed by 40 cycles, each composed of a denaturation step $\left(95^{\circ} \mathrm{C}\right.$ for $15 \mathrm{~s})$ and a primer annealing/extension step $\left(60^{\circ} \mathrm{C}\right.$ for $45 \mathrm{~s})$. Melting curves were performed to ensure sufficient PCR product was being generated by each primer, in the absence of primer dimers. All assays were performed in duplicate (coefficient of variation $=0.01$ ).

mRNA expression data were calculated using the Livak method [36], and data are presented as the fold change of the gene of interest, relative to that of control animals.

Table 2 Primer sequences used in quantitative reverse transcription polymerase chain reactions

\begin{tabular}{ll}
\hline Target & Primer sequence $\left(5^{\prime}-3^{\prime}\right)$ \\
\hline Fan1 forward primer & CTITATCAGCGAGCTGTGCG \\
Fan1 reverse primer & CACAGACTTGCCCATCCCAT \\
Mrella forward primer & CAAGGAAAACCCTGCACAGC \\
Mrella reverse primer & CCTAAGCCGTACAGAGCGAG \\
Telomere forward primer & GGTIITGAGGGTGAGGGTG \\
Telomere reverse primer & AGGGGAGGGGAGGGT \\
& CCCCGACTATCCCTATCCCTAT \\
Gapdh forward primer & GTTACCAGGGCTGCCTTCTC \\
Gapdh reverse primer & GATGGTGATGGGTTCCCGT \\
\hline Fan1 Fanconi anaemia-associated nuclease 1, Mre11a meiotic recombination \\
11 homolog A, Gapdh glyceraldehyde 3-phosphate dehydrogenase
\end{tabular}

Relative telomere length was assessed using methods described in detail elsewhere, [20,37, 38]. Briefly, relative telomere length was quantified by determining the ratio (T/S ratio) of telomere repeat copy number ( $\mathrm{T}$ ) to single control gene copy number (S), relative to a reference sample. In this study, Gapdh was used as the single control gene.

\section{Clinical Measurements}

Detailed methods describing the collection and analysis of clinical measurements, in the animals discussed in the current study, have been previously reported [27]. Briefly, clinical measures included systolic blood pressure, remnant kidney weight, remnant kidney weight to body weight ratio, and plasma levels of high-density lipoprotein, low-density lipoprotein, triglycerides, total cholesterol, albumin, and creatinine. These measurements receive consideration in the "Discussion" section of this manuscript as they help elucidate mechanisms that may relate to findings in the current study.

\section{Statistics}

Data related to mRNA are presented as mean \pm standard error of the mean (SEM). Data for mRNA expression were analysed using separate between-group one-way ANOVAs with Tukey's post hoc comparisons. Analyses were performed using IBM SPSS Statistics (v20.0, IBM Corporation; Armonk, NY, USA). Statistical significance was set at $p<0.05$.

\section{Results}

\section{Clinical Measurements}

Clinical measurements relating to the animals in the current investigation have been previously reported [27]. A summary of these results can be found in Table 3 (republished with permission).

\section{Quantitative Reverse Transcription Polymerase Chain Reaction Analysis}

Results pertaining to renal expression of mRNA related to genomic health can be seen in Fig. 2a-c. In HIIT, mRNA expression of Fan1 was significantly upregulated, compared to $\operatorname{SED}(p=0.026)$ and $\mathrm{T} / \mathrm{S}$ ratio was significantly increased, compared to SED $(p<0.001)$ and LIT $(p=0.002)$. There were no significant betweengroup differences for Mre11a (HIIT v. SED, $p=0.184$; HIIT v. LIT, $p=0.327$ ).

\section{Discussion}

This is the first investigation to assess and compare the ability of SED, LIT, and HIIT to modulate kidneyspecific mRNA expression of genes related to genomic integrity, in an experimental model of early-stage CKD. In fact, except for a handful of studies that have examined 
Table 3 Previously reported clinical measures. Reproduced from Tucker et al. [27] with permission

\begin{tabular}{|c|c|c|c|c|c|}
\hline Measure & Previously reported & Group & Mean & $p$ value compare to HIIT & Mean duplicate CV \\
\hline \multirow[t]{3}{*}{$\mathrm{HDL}(\mathrm{mg} / \mathrm{ml})$} & \multirow[t]{3}{*}{ Yes } & SED & $0.82 \pm 0.13$ & 0.109 & \multirow[t]{3}{*}{0.06} \\
\hline & & LIT & $0.88 \pm 0.15$ & 0.591 & \\
\hline & & HIIT & $0.93 \pm 0.12$ & & \\
\hline \multirow[t]{3}{*}{$\mathrm{LDL}(\mathrm{mg} / \mathrm{ml})$} & \multirow[t]{3}{*}{ Yes } & SED & $1.27 \pm 0.27$ & 0.285 & \multirow[t]{3}{*}{0.03} \\
\hline & & LIT & $1.55 \pm 0.34$ & 0.001 & \\
\hline & & HIIT & $1.08 \pm 0.32^{\mathrm{a}}$ & & \\
\hline \multirow[t]{3}{*}{ TAG (mg/ml) } & \multirow[t]{3}{*}{ Yes } & SED & $5.65 \pm 1.66$ & 0.183 & \multirow[t]{3}{*}{.04} \\
\hline & & LIT & $6.35 \pm 2.65$ & 0.029 & \\
\hline & & HIIT & $4.11 \pm 2.04^{\mathrm{a}}$ & & \\
\hline \multirow[t]{3}{*}{$\mathrm{CHOL}(\mathrm{mg} / \mathrm{ml})$} & \multirow[t]{3}{*}{ Yes } & SED & $3.22 \pm 0.47$ & 0.263 & \multirow[t]{3}{*}{ NA } \\
\hline & & LIT & $3.71 \pm 0.61$ & 0.002 & \\
\hline & & HIIT & $2.83 \pm 0.73^{\mathrm{a}}$ & & \\
\hline \multirow[t]{3}{*}{ CRE (nmol/ul) } & \multirow[t]{3}{*}{ Yes } & SED & $1.07 \pm 0.51$ & 0.126 & \multirow[t]{3}{*}{0.04} \\
\hline & & LIT & $2.06 \pm 1.79$ & 0.996 & \\
\hline & & HIIT & $2.11 \pm 1.26$ & & \\
\hline \multirow[t]{3}{*}{ ALB $(\mathrm{mg} / \mathrm{ml})$} & \multirow[t]{3}{*}{ Yes } & SED & $26.23 \pm 3.84$ & 0.001 & \multirow[t]{3}{*}{0.04} \\
\hline & & LIT & $29.88 \pm 6.42$ & 0.047 & \\
\hline & & HIIT & $35.24 \pm 6.08^{b}$ & & \\
\hline \multirow[t]{3}{*}{ Kidney weight (g) } & \multirow[t]{3}{*}{ Yes } & SED & $1.57 \pm 0.09$ & 0.028 & \multirow[t]{3}{*}{$N A^{c}$} \\
\hline & & LIT & $1.59 \pm 0.12$ & 0.005 & \\
\hline & & HIIT & $1.46 \pm 0.08^{b}$ & & \\
\hline \multirow[t]{3}{*}{ KW-BW ratio } & \multirow[t]{3}{*}{ Yes } & SED & $0.005 \pm 0.0003$ & 0.045 & \multirow[t]{3}{*}{ NA } \\
\hline & & LIT & $0.005 \pm 0.0003$ & 0.048 & \\
\hline & & HIIT & $0.0047 \pm 0.0002^{b}$ & & \\
\hline \multirow[t]{3}{*}{ Post-In SBP (mmHg) } & \multirow[t]{3}{*}{ Yes } & SED & $239.77 \pm 12.85$ & 0.114 & \multirow[t]{3}{*}{0.02} \\
\hline & & LIT & $241.63 \pm 21.42$ & 0.074 & \\
\hline & & HIIT & $227.12 \pm 14.23$ & & \\
\hline
\end{tabular}

Values presented as mean \pm standard deviation

Values are re-reported with permission

Significance set at $p<0.05$

SED sedentary, LIT light-intensity exercise, HIIT high-intensity interval training, $H D L$ high-density lipoprotein, $L D L$ low-density lipoprotein, $T A G$ triglycerides, $C H O L$

total cholesterol, $C R E$ creatinine, $A L B$ albumin, $K W-B W$ kidney weight-body weight, Post-Int SBP post-intervention systolic blood pressure, $C V$ coefficient of variation

${ }^{a}$ HIIT significantly different from LIT

${ }^{\mathrm{b}} \mathrm{HIIT}$ significantly different from LIT and SED

${ }^{\mathrm{C}} \mathrm{CHOL}$ is a calculated value and does not have a duplicate $\mathrm{CV}$

the relationship between chronic exercise and telomere length [39-43], we are unaware of any investigations that have assessed the ability of exercise, of any mode or duration, to modulate mRNA expression of genes related to genomic integrity (specifically, Mre11a and Fan1), in any tissue or disease model. As a result, little is known about the effects of chronic exercise on genes related to genomic integrity. There is, however, evidence to attest that chronic aerobic exercise can beneficially influence health-related markers and that these beneficial effects are further enhanced by increases in exercise intensity [29, 30, 44, 45]. This evidence provides a reasonable basis for two assumptions that are supported by the current findings: (a) some beneficial effects of chronic aerobic exercise may stem from genome-based genomic protection (i.e. genes that protect genes) and (b) some chronic exercise-mediated effects related to genomic protection may be further enhanced by increases in exercise intensity.

Using an animal model of progeroid aging that exhibits elevated mitochondrial DNA point mutations and systemic mitochondrial dysfunction, Safdar et al. reported 5 months of endurance exercise $(15 \mathrm{~m} / \mathrm{min}$ for 45 min, 3 times/week) mitigated mitochondrial DNA depletion and point mutations in the skeletal muscle, heart, and liver of mice [42]. However, the mechanisms that explain these positive, exercise-related effects 


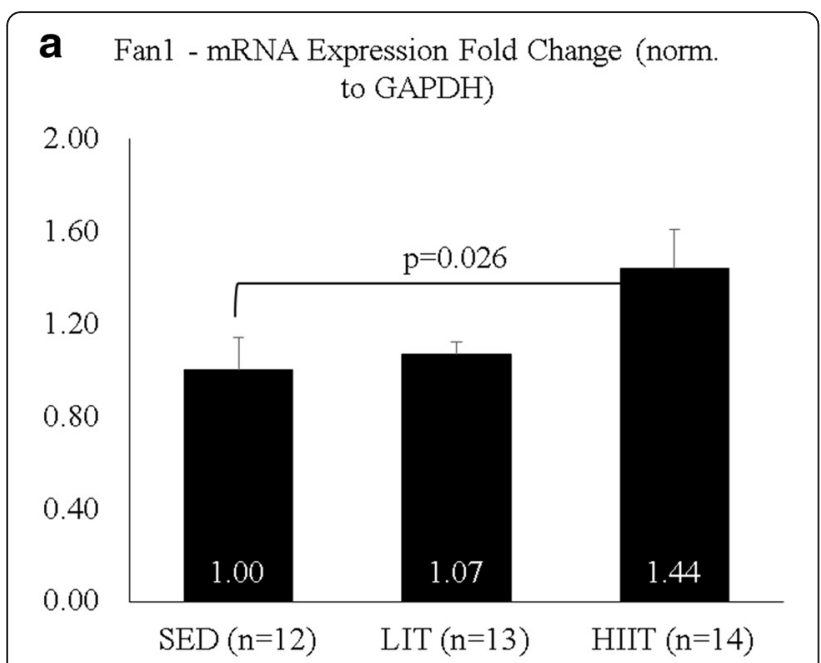

b Mre1la - mRNA Expression Fold Change (norm. to GAPDH)

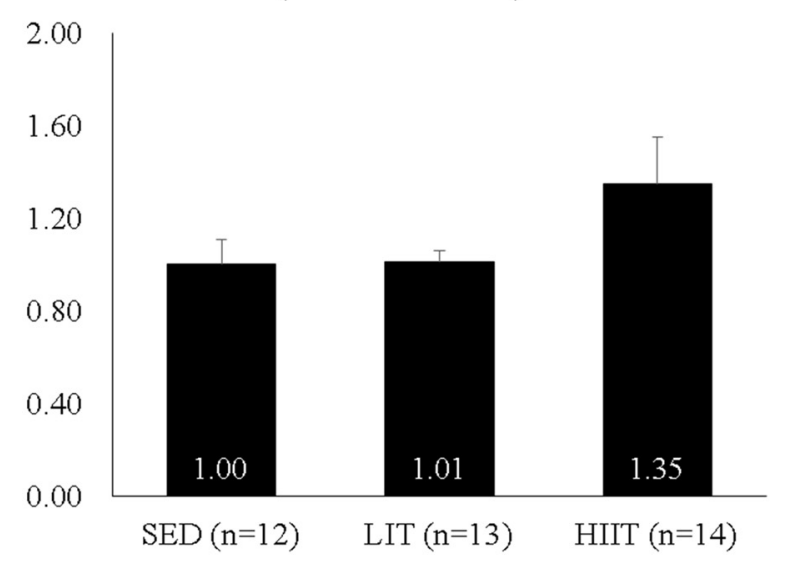

c $\quad \mathrm{T} / \mathrm{S}$ Ratio

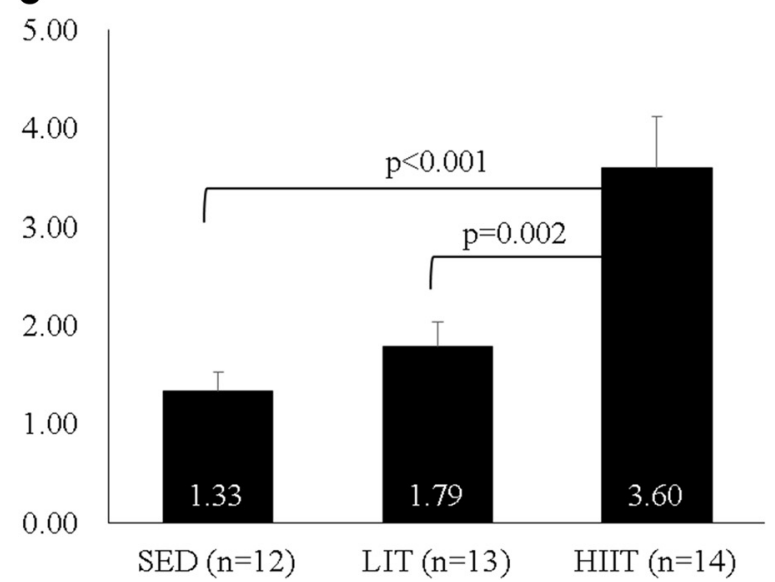

Fig. 2 a-c mRNA related to genomic health-expression fold change

remain unclear. Results from our study suggest that HIIT may preserve genomic integrity in the kidney, in part, by significant exercise-induced increases to renal expression of Fan1 mRNA (v. SED). Unlike Safdar et al., our data suggests that changes to indices of genomic integrity may be intensity-dependant as HIIT was the only exercise condition that stimulated significant increases in Fan1 mRNA expression (v. SED) and T/S Ratio (v. SED and LIT). However, there are several explanations that may account for the discrepancy between our data and data reported by Safdar et al., including training duration and disease model.

Work regarding Fan1 gene expression has determined that the resultant protein is a required component of resistance against harmful DNA crosslinking [12-14] and is likely involved in other forms of DNA damage repair $[46,47]$. This, combined with our current results, leads us to suggest that HIIT-induced increases in renal expression of Fan1 mRNA are a beneficial adaptation that may partially explain other beneficial, renal-specific, HIIT-related effects in this group of animals. Specifically, we previously reported that plasma albumin and kidney weight-body weight ratio were significantly improved by HIIT (v. SED and LIT) in the same animals being examined in the current study [30]. This finding aligns with data that suggests blunted DNA repair, stemming from Fan1 mutations or depletions, leads to interstitial nephritis [14], a condition associated with proteinuria and renal hypertrophy [48].

Renal T/S ratio, an indicator of telomere length, was also beneficially influenced by HIT in the current study (v. SED and LIT). This may be partially due to nonsignificant increases in renal expression of Mre11a mRNA in HIIT. Research suggests that the MRN complex, whose core is encoded by the gene Mre11a, is required for the phosphorylation of TRF1, a telomeric repeat binding factor [19]. The phosphorylation of TRF1 results in the release of TRF1 from telomeres, thereby allowing telomerase, a ribonucleoprotein that adds the nucleotide "TTAGGG" to the 3' end of telomeres, access to the ends of telomeres [19]. Simply put, the nonsignificant, HIIT-related increase in renal expression of Mre11a mRNA may have helped to preserve renal telomere length by allowing telomerase access to the ends of telomeres. That said, it is unlikely that non-significant increases in the renal expression of Mre11a mRNA fully explain the significant HIIT-related increases in renal T/S ratio (v. SED and LIT) seen in the current study.

Despite previous work performed in this area [39-41, 43], the mechanisms that allow for telomere preservation, following chronic aerobic exercise, are elusive. Similar to our results, previous work has suggested that chronic exercise can beneficially influence telomere length [40, 41]. What is less understood is the effect that exercise intensity has on telomere length. One study suggests that leukocyte telomere length is (1) preserved in adults who chronically and vigorously exercise and is (2) related to maximal aerobic capacity [40]. However, 
data from this study is cross-sectional and the exercise "intensity" discussed is not well defined [40]. Conversely, another study suggests that telomere length, in peripheral blood mononuclear cells, is best preserved by moderate levels of chronic physical activity, compared to low and high levels of physical activity [43]. However, this study categorized participants based on cross-sectional exercise energy expenditure data that was assessed via survey [43]. As such, and to our knowledge, this is the first study to explicitly examine the effect of exercise intensity on telomere length, regardless of tissue or disease model.

Aside from non-significant increases in the renal expression of Mre11a mRNA, there is evidence to suggest that significant HIIT-related increases in renal mRNA expression of antioxidant enzymes may help to explain the significant HIIT-related increase in renal T/S ratio. Reviewed elsewhere [49], telomeric DNA appears to be especially susceptible to attack by reactive oxygen species. We previously reported [31], in the same group of animals, that HIIT resulted in significant increases in the renal mRNA expression of the antioxidant enzymes superoxide dismutase (v. SED) and catalase (v. SED and LIT). Given the significant HIIT-related increases in the renal mRNA expression of superoxide dismutase (v. SED) and catalase (v. SED and LIT) [31], we suggest that significant HIIT-related increases to renal T/S ratio (v. SED and LIT) may have been influenced by concomitant increases in the renal mRNA expression of antioxidant enzymes. This assertion is supported by previous work performed in rats where increased oxidative stress was related to accelerated telomere shortening and decreased renal function [50].

\section{Conclusions}

Our data indicated that HIIT was responsible for a significant up-regulation in the renal expression of Fan1 mRNA (v. SED) and increases to renal T/S ratio (v. SED and LIT). The significant HIIT-related increases to renal $\mathrm{T} / \mathrm{S}$ ratio may be partially explained by non-significant HIIT-related increases to renal expression of Mre1la mRNA. The significant HIITrelated increases to renal $\mathrm{T} / \mathrm{S}$ ratio may also be partially explained by significant HIIT-related increases in renal mRNA expression of superoxide dismutase (v. SED) and catalase (v. SED and LIT). Combined with previously published data from our laboratory [30, 31], the current investigation provides compelling evidence that HIIT is superior to SED and LIT in regard to the preservation of genomic integrity in the kidney, making HIIT a promising therapy for patients with early-stage CKD. Clinical trials should be conducted in humans to further explore the use of HIIT as a means by which to slow disease progression in early-stage CKD populations.

\section{Authors' Contributions}

PST co-developed the research idea, co-developed the methods, planned and undertook the literature review, performed and interpreted the analysis, wrote the first draft of the manuscript, edited the manuscript based on co-author feedback, submitted the manuscript, prepared and submitted the revisions, and managed the publication of the manuscript. ATS reviewed the draft of the manuscript and reviewed the responses to the reviewers. RKV reviewed the draft of the manuscript, co-developed the methods, and performed and interpreted the analysis. VJD co-developed the research idea and methods, reviewed the draft of the manuscript, and reviewed the responses to the reviewers. All authors read and approved the final manuscript.

\section{Competing Interests}

Patrick S. Tucker, Aaron T. Scanlan, Rebecca K. Vella, and Vincent J. Dalbo declare that they have no conflict of interest.

\section{Author details}

${ }^{1}$ Clinical Biochemistry Laboratory, School of Medical and Applied Sciences, Central Queensland University, Bruce Highway, Building 81, Room 1.11, Rockhampton 4702, Queensland, Australia. ${ }^{2}$ Human Exercise and Training Laboratory, Central Queensland University, Bruce Highway, Building 81, Rockhampton 4702, Australia. ${ }^{3}$ Cardiovascular Pharmacology Laboratory, Central Queensland University, Bruce Highway, Building 81, Rockhampton 4702, Australia.

Received: 29 March 2016 Accepted: 26 July 2016

Published online: 09 August 2016

\section{References}

1. Tucker PS, et al. The increasing financial impact of chronic kidney disease in Australia. Int J Nephrol. 2014;2014:120537.

2. Go AS, et al. Chronic kidney disease and the risks of death, cardiovascular events, and hospitalization. N Engl J Med. 2004:351(13):1296-305.

3. Weiner DE, et al. Chronic kidney disease as a risk factor for cardiovascular disease and all-cause mortality: a pooled analysis of community-based studies. J Am Soc Nephrol. 2004;15(5):1307-15.

4. Trachootham D, et al. Redox regulation of cell survival. Antioxid Redox Signal. 2008;10(8):1343-74.

5. Cooke MS, et al. Oxidative DNA damage: mechanisms, mutation, and disease. FASEB J. 2003;17(10):1195-214

6. Gates KS. An overview of chemical processes that damage cellular DNA: spontaneous hydrolysis, alkylation, and reactions with radicals. Chem Res Toxicol. 2009;22(11):1747-60.

7. Evans MD, Dizdaroglu M, Cooke MS. Oxidative DNA damage and disease: induction, repair and significance. Mutat Res. 2004;567(1):1-61.

8. Tucker PS, Scanlan AT, Dalbo VJ. Chronic kidney disease influences multiple systems: describing the relationship between oxidative stress, inflammation, kidney damage, and concomitant disease. Oxid Med Cell Longev. 2015;2015:806358

9. Kao MP, et al. Oxidative stress in renal dysfunction: mechanisms, clinical sequelae and therapeutic options. J Hum Hypertens. 2010;24(1):1-8.

10. Jones MJ, Huang TT. The Fanconi anemia pathway in replication stress and DNA crosslink repair. Cell Mol Life Sci. 2012;69:3963-74.

11. Kim H, D'Andrea AD. Regulation of DNA cross-link repair by the Fanconi anemia/BRCA pathway. Genes Dev. 2012;26(13):1393-408.

12. Smogorzewska A, et al. A genetic screen identifies FAN1, a Fanconi anemiaassociated nuclease necessary for DNA interstrand crosslink repair. Mol Cell. 2010;39(1):36-47.

13. Kratz K et al. Deficiency of FANCD2-associated nuclease KIAA1018/FAN1 sensitizes cells to interstrand crosslinking agents. Cell. 2010;142(1):77-88.

14. Zhou W, et al. FAN1 mutations cause karyomegalic interstitial nephritis, linking chronic kidney failure to defective DNA damage repair. Nat Genet. 2012:44(8):910-5.

15. D'Amours D, Jackson SP. The Mre11 complex: at the crossroads of DNA repair and checkpoint signalling. Nat Rev Mol Cell Biol. 2002;3(5):317-27.

16. Sheen MR, et al. Mre11-Rad50-Nbs1 complex is activated by hypertonicity. Am J Physiol Renal Physiol. 2006;291(5):F1014-20.

17. Kim YJ, et al. Expression of the Mre11-Rad50-Nbs1 complex in cisplatin nephrotoxicity. Environ Toxicol Pharmacol. 2015;40(1):12-7.

18. Lee $J H$, Paull TT. ATM activation by DNA double-strand breaks through the Mre11-Rad50-Nbs1 complex. Science. 2005;308(5721):551-4. 
19. Wu Y, Xiao S, Zhu XD. MRE11-RAD50-NBS1 and ATM function as co-mediators of TRF1 in telomere length control. Nat Struct Mol Biol. 2007;14(9):832-40.

20. Heidinger BJ, et al. Telomere length in early life predicts lifespan. Proc Natl Acad Sci U S A. 2012;109(5):1743-8.

21. Rode L, Nordestgaard BG, Bojesen SE. Peripheral blood leukocyte telomere length and mortality among 64,637 individuals from the general population. J Natl Cancer Inst. 2015;107(6):djv074.

22. Fyhrquist $F$, et al. Telomere length and progression of diabetic nephropathy in patients with type 1 diabetes. J Intern Med. 2010;267(3):278-86.

23. Wong LS, et al. Renal dysfunction is associated with shorter telomere length in heart failure. Clin Res Cardiol. 2009;98(10):629-34.

24. Agarwal D, et al. Chronic exercise preserves renal structure and hemodynamics in spontaneously hypertensive rats. Antioxid Redox Signal. 2012:16(2):139-52.

25. de Souza PS, et al. Therapeutic action of physical exercise on markers of oxidative stress induced by chronic kidney disease. Life Sci. 2012;91(3-4):132-6.

26. Howden EJ, et al. Exercise training in chronic kidney disease patients. Sports Med. 2012;42(6):473-88.

27. Tucker PS, Scanlan AT, Dalbo VJ. High intensity interval training favourably affects angiotensinogen mRNA expression and markers of cardiorenal health in a rat model of early-stage chronic kidney disease. Biomed Res Int. 2015;2015:156584

28. Kessler HS, Sisson SB, Short KR. The potential for high-intensity interval training to reduce cardiometabolic disease risk. Sports Med. 2012;42(6):489-509.

29. Powers SK, et al. Rigorous exercise training increases superoxide dismutase activity in ventricular myocardium. Am J Physiol. 1993;265(6 Pt 2):H2094-8.

30. Tucker PS, Scanlan AT, Dalbo VJ. High intensity interval training favourably affects angiotensinogen mRNA expression and markers of cardiorenal health in a rat model of early-stage chronic kidney disease. BioMed Res Int. 2015;2015:156584

31. Tucker PS, Briskey DR, Scanlan AT, Coombes JS, Dalbo VJ. High intensity interval training favourably affects antioxidant and inflammation mRNA expression in early-stage chronic kidney disease. Free Radic Biol Med. 2015;89:466-72

32. Brooks GA, White TP. Determination of metabolic and heart rate responses of rats to treadmill exercise. J Appl Physiol Respir Environ Exerc Physiol. 1978;45(6):1009-15.

33. Yu Y, et al. A rat RNA-Seq transcriptomic BodyMap across 11 organs and 4 developmental stages. Nat Commun. 2014;5:3230.

34. Marques FZ, et al. Gene expression profiling reveals renin mRNA overexpression in human hypertensive kidneys and a role for microRNAs. Hypertension. 2011;58(6):1093-8.

35. Jemiolo B, Trappe S. Single muscle fiber gene expression in human skeletal muscle: validation of internal control with exercise. Biochem Biophys Res Commun. 2004;320(3):1043-50.

36. Livak KJ, Schmittgen TD. Analysis of relative gene expression data using real-time quantitative $P C R$ and the 2(-delta delta $C(T)$ ) method. Methods. 2001;25(4):402-8.

37. Cawthon RM. Telomere measurement by quantitative PCR. Nucleic Acids Res. 2002;30(10):e47.

38. Bize $P$, et al. Telomere dynamics rather than age predict life expectancy in the wild. Proc Biol Sci. 2009;276(1662):1679-83.

39. Osthus IB, et al. Telomere length and long-term endurance exercise: does exercise training affect biological age? A pilot study. PLoS One. 2012;7(12):e52769.

40. LaRocca TJ, Seals DR, Pierce GL. Leukocyte telomere length is preserved with aging in endurance exercise-trained adults and related to maximal aerobic capacity. Mech Ageing Dev. 2010;131(2):165-7.

41. Puterman $\mathrm{E}$, et al. The power of exercise: buffering the effect of chronic stress on telomere length. PLoS One. 2010;5(5):e10837.

42. Safdar A, et al. Endurance exercise rescues progeroid aging and induces systemic mitochondrial rejuvenation in mtDNA mutator mice. Proc Natl Acad Sci U S A. 2011;108(10):4135-40.

43. Ludlow AT, et al. Relationship between physical activity level, telomere length, and telomerase activity. Med Sci Sports Exerc. 2008;40(10):1764-71.

44. Moreira JB, et al. High- versus moderate-intensity aerobic exercise training effects on skeletal muscle of infarcted rats. J Appl Physiol. 2013;114(8):1029-41.

45. Nagasawa J, et al. Exercise intensity and antioxidant ability. Rejuvenation Res. 2010;13(2-3):172-4.
46. Moldovan GL, D'Andrea AD. How the fanconi anemia pathway guards the genome. Annu Rev Genet. 2009:43:223-49.

47. Dunn J, et al. Activation of the Fanconi anemia/BRCA pathway and recombination repair in the cellular response to solar ultraviolet light. Cancer Res. 2006;66(23):11140-7.

48. Hodgkins KS, Schnaper HW. Tubulointerstitial injury and the progression of chronic kidney disease. Pediatr Nephrol. 2012;27(6):901-9.

49. Houben JM, et al. Telomere length assessment: biomarker of chronic oxidative stress? Free Radic Biol Med. 2008:44(3):235-46.

50. Tarry-Adkins JL, et al. Lower antioxidant capacity and elevated p53 and p21 may be a link between gender disparity in renal telomere shortening, albuminuria, and longevity. Am J Physiol Renal Physiol. 2006;290(2):F509-16.

\section{Submit your manuscript to a SpringerOpen ${ }^{\circ}$ journal and benefit from:}

- Convenient online submission

- Rigorous peer review

- Immediate publication on acceptance

- Open access: articles freely available online

- High visibility within the field

- Retaining the copyright to your article

Submit your next manuscript at springeropen.com 